\title{
HIGHLIGHT
}

\section{Roads to pluripotency}

\author{
Yongfeng SHANG \\ Peking University Health Science Center, Beijing 100191, China
}

(C) Higher Education Press and Springer-Verlag Berlin Heidelberg 2010

One of the hottest technologies used for nuclear reprogramming in these days is the induction of pluripotent stem (iPS) cells by defined molecules. This is exemplified by the recent generation of viable, live-born, and fertile mice through tetraploid complementation by Zhou's lab (Zhao et al., 2009), thus having demonstrated for the first time the true pluripotency of iPS cells as ES cells. In this issue of Frontiers in Biology, a short review (Li and Zhou, 2009) entitled "Epigenetic reprogramming: roads to pluripotency" (DOI 10.1007/s11515-010-0003-z) by Wei Li and Qi Zhou of Chinese Academy of Sciences, Beijing, China, summarized several methodologies concerning epigenetic reprogramming, including somatic cell nuclear transfer, cell fusion, cell extract treatment, inducing pluripotency by defined factors, and discussed their advantages and limitations. Together with the interesting story of their own, the authors discussed the generation of iPS cells and the identification of pluripotency, from chimeras with germ line transmission to the gold standard - tetraploid complementation assay. Compared to ES cells, iPS cells have few ethical concerns and are better model systems for the mechanistic study of reprogramming.

\section{References}

Li W, Zhou Q (2009). Epigenetic reprogramming: roads to pluripotency. Front. Biol. DOI 10.1007/s11515-010-0003-Z

Zhao X Y, Li W, Lv Z, Liu L, Tong M, Hai T, Hao J, Guo C L, Ma Q W, Wang L, Zeng F, Zhou Q (2009). iPS cells produce viable mice through tetraploid complementation. Nature, 461: 86-90

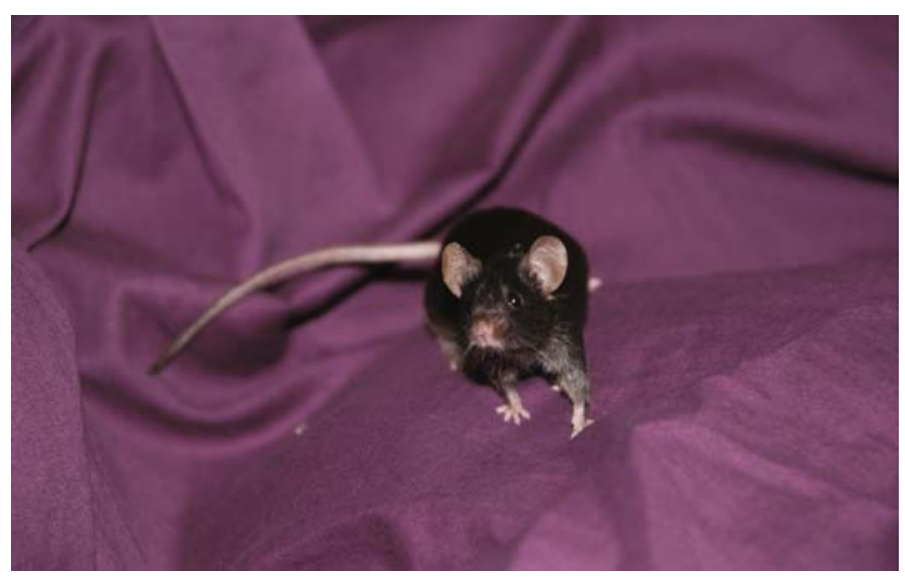

Received December 18, 2009; accepted December 21, 2009

E-mail: yshang@hsc.pku.edu.cn 